\title{
PROJETOS DE FORMAÇÃO E REPERCUSSÕES PARA A VIDA PRÁTICA: UM ESTUDO COM ALUNOS EGRESSOS DA EJA
}

\author{
Cláudia Regina Alves dos Santos ${ }^{1}$ \\ (iD https://orcid.org/0000-0001-8870-4763 \\ Magda Madalena Tuma² \\ https://orcid.org/0000-0003-0805-839X
}

Resumo: Esta pesquisa tem o objetivo de reconhecer repercussões para a vida prática trazida por formação realizada no CEBJA do SESC em Londrina/PR, por grupo de doze egressos de EJA que lá estudaram entre os anos de 2004 a 2007. Utilizamos os pressupostos metodológicos de Christine Delory-Momberger (2008), que sugere procedimentos de coleta de dados em 'ateliês biográficos de projeto' em que, organizados em tríades expressam memórias e histórias de vida com narrativas no coletivo, sobre os processos de formação antes, durante e após o período escolar. A mesma visa à análise da formação e também da revisão dos projetos concretizados ou não em suas vidas. Josso (1999) e Pollak (1992), entre outros autores, vêm colaborar com a pesquisa bibliográfica, esclarecendo os percursos seguidos e as categorias elencadas. Também analisamos a EJA, as metodologias e impactos da formação na vida prática dos egressos. Os resultados da pesquisa foram articulados às temáticas trabalhadas, contemplando deslocamentos temporais que puderam demonstrar algumas repercussões na vida destes sujeitos. Nas considerações finais, retomamos a análise dos objetivos da pesquisa e concluímos referendando a proposição metodológica como mais um instrumento de eficácia formativa nos espaços em que a pesquisa científica se faz necessária.

Palavras-chave: Memória. Narrativas. Histórias de vida. Projetos

1 Mestre em Educação pela Universidade Estadual de Londrina. Professora Colaboradora na Universidade Estadual de Londrina. E-mail: claudialda@hotmail.com

2 Pós-doutorado em Educação na Universidade de São Paulo. Doutora em Educação pela Universidade Estadual de Campinas. Professora da Universidade Estadual de Londrina 


\title{
IMPACTS OF EJA TRAINING ON THE LIFE STUDENTS OF GRADUATED STUDENTS
}

\begin{abstract}
This research was carried out at Cebja do SESC in Londrina / PR, with a group of twelve graduates of EJA who studied there between the years 2004 to 2007 . Our objective was to know the repercussions of training in the lives of these graduates. We use the methodological assumptions of Christine Delory-Momberger (2008), who suggests data collection procedures in 'biographical project studios' in which, organized in triads, express memories and life stories with narratives in the collective, about the formation processes before, during and after school. It aims at analyzing training and also at reviewing projects that have been implemented or not in their lives. Josso (1999) and Pollak (1992), among other authors, have collaborated with the bibliographic research, clarifying the paths followed and the categories listed. We also analyzed the EJA, the methodologies and impacts of the training in the practical life of the graduates. The research results were articulated with the themes worked on, contemplating temporal displacements that could demonstrate some repercussions in the lives of these subjects. In the final remarks, we return to the analysis of the research objectives and conclude by endorsing the methodological proposal as another instrument of formative effectiveness in the spaces where scientific research is necessary.
\end{abstract}

Keywords: Memory. Narratives. Life stories. Projects.

\section{IMPACTOS DE LA FORMACIÓN EJA EN LOS ESTUDIANTES DE LA VIDA DE ESTUDIANTES GRADUADOS}

Resumen: Esta investigación se llevó a cabo en Cebja do SESC en Londrina / PR, con un grupo de doce graduados de EJA que estudiaron allí entre los años 2004 a 2007. Nuestro objetivo era conocer las repercusiones de la capacitación en la vida de estos graduados. Utilizamos los supuestos metodológicos de Christine Delory-Momberger (2008), quien sugiere procedimientos de recopilación de datos en 'estudios de proyectos biográficos' en los que, organizados en tríadas, expresan recuerdos e historias de vida con narraciones en el colectivo, sobre los procesos de formación anteriores, durante y después de la escuela. Su objetivo es analizar la capacitación y también revisar los proyectos que se han implementado o no en sus vidas. Josso (1999) y Pollak (1992), entre otros autores, colaboran con la investigación bibliográfica, aclarando los caminos seguidos y las categorías enumeradas. También analizamos EJA, las metodologías e impactos de la capacitación en la vida práctica de los graduados. Los resultados de la investigación se articularon con los temas trabajados, contemplando desplazamientos temporales que podrían demostrar algunas repercusiones en la vida de estos sujetos. En las observaciones finales, volvemos al análisis de los objetivos de la investigación y concluimos respaldando la propuesta metodológica como otro instrumento de efectividad formativa en los espacios donde es necesaria la investigación científica.

Palabras clave: Memoria. Narrativas. Historias de vida. Proyectos 


\section{Introdução}

0 presente estudo faz parte da dissertação de mestrado, na qual, focamos a Educação de Jovens e Adultos (EJA) tendo por campo a Instituição SESC - Serviço Social do Comércio, na cidade de Londrina-Paraná, no ano de 2011 e 2012. A instituição foi escolhida por ofertar esta modalidade de ensino nos níveis fundamental Il e nível médio.

Objetivando o acesso às repercussões do processo de formação na Educação de Jovens e Adultos (EJA) foi campo deste estudo uma unidade executiva do SESC em Londrina, onde dialogamos com sujeitos sociais egressos da instituição nos anos de 2004 a 2007 e que já estivessem nesta condição há pelo menos dois anos. Nosso objetivo foi a aproximação ao conhecimento dos educandos egressos acerca desse processo e da repercussão sobre os projetos de vida prática que a formação motivou. Assim, constituímos um grupo de 'doze alunos egressos' para a análise do percurso anterior e posterior ao processo de formação na Educação de Jovens e Adultos e desta forma abarcar relações temporais entre o presente, o passado e projeções para o futuro, promovendo diálogo com e entre os mesmos, tal como preconiza Delory-Momberger ${ }^{3}$ (2008, p. 99).

As questões norteadoras ou temáticas desta pesquisa estiveram diretamente relacionadas aos projetos pessoais dos alunos que passaram pela EJA na instituição pesquisada, tendo sido a primeira relacionada à trajetória e os processos de escolarização vividos antes do ingresso na EJA, a segunda abordou a experiência escolar durante o processo de formação no interior da instituição e por último, as repercussões do processo de formação e relevância sobre os projetos profissionais na vida prática.

Reconhecer em qual dimensão a instituição de caráter privado como o SESC realiza ou não um trabalho significativo em educação, fazendo valer os objetivos contidos nos documentos norteadores de suas ações fez parte deste estudo ao serem estas instituições mantidas também com recursos públicos, oriundos de impostos, e que, a exemplo de outras instituições também privadas, adentram o campo educacional. Para tanto, buscamos situá-lo nos diversos contextos necessários à compreensão da repercussão que efetiva sobre alunos egressos em seu processo de escolarização. Tal condição o constituiu como campo deste estudo para o acesso às memórias, às histórias de vida e narrativas dos

\footnotetext{
3 Dra Christine Delory-Momberger, docente do Departamento de Ciências da Educação da Universidade de Paris $13 /$ Nord.
} 
alunos egressos, o que também remeteu à análise de documentos produzidos pelo SESC em seus objetivos de forma geral, assim como a Proposta Político-Pedagógica voltada para a EJA.

Os pressupostos metodológicos de Christine Delory-Momberger (2008) nortearam nossos encaminhamentos em relação aos procedimentos de coleta de dados através dos 'ateliês biográficos de projeto', os quais consistem no trabalho com a memória expressa em narrativas, que têm por referência o processo de formação nas histórias de vida, abarcando diferentes temporalidades para a análise da formação realizada e a revisão dos projetos concretizados ou não pelos participantes em sua vida prática após este processo formativo. Autores como Josso (1999), Pollak (1992), entre outros vêm colaborar na pesquisa bibliográfica, de forma a esclarecer este percurso metodológico e os conceitos por nós utilizados no decorrer da pesquisa em questão.

\section{Narrativa, Oralidade e Memória}

A necessidade de aprofundamento das teorias correspondentes aos procedimentos arrolados para a pesquisa nos levou a estudos sobre história oral, narrativa, memória e biografia. Os depoimentos produzidos pelas tríades no coletivo foram analisados como depoimento-documento, na consideração de que tal procedimento nos possibilita por meio da análise das narrativas o reconhecimento das “[...] representações que dão aos formatos de suas experiências de formação, reinscrevendo-as em suas narrativas na perspectiva de um projeto" (DELORY-MOMBERGER, 2008, p. 99)

A análise das repercussões do 'fazer pedagógico' do SESC Londrina, na perspectiva de egressos para a realização dos projetos de vida/formação, favorecidos ou não por sua inserção na EJA, nos remeteu à abordagem qualitativa. São os estudos relacionados à proposição de Delory-Momberger (2008, p. 99-104) que nos subsidiaram para o registro das histórias de vida em uma dinâmica prospectiva, o que nos propiciou contexto para deslocamentos temporais em suas três dimensões (passado, presente e futuro).

Segundo Delory-Momberger (2008), a preocupação com as relações estabelecidas entre a forma pela qual os indivíduos representam suas vidas e como adquirem competências e saberes sobre o mundo e sobre si mesmos nos espaços de vivência como a família, a escola e a sociedade são fundamentais como premissa para compreendermos 
o processo de formação desses mesmos indivíduos, bem como os significados construídos antes, durante e após essas experiências, somadas às expectativas de futuro geradas.

A autora anuncia que no mundo atual se faz presente a 'figura do indivíduo-projeto', ou seja, aquele que se percebe no que está sendo, no que já não pode ser e no que ainda pode vir a ser, numa ideia semelhante ao 'vir a ser' suscitada por Freire (1997) quando menciona: “Gosto de ser gente, porque, inacabado, sei que sou um ser condicionado, mas, consciente do inacabamento, sei que posso ir mais além dele” (FREIRE,1997, p. 23).

A partir desta perspectiva, este estudo visou colocar sujeitos que viveram/conviveram no mesmo período de formação, em situações de rememoração para que, no diálogo, expressassem os sentidos atribuídos a esta 'formação' na relação com seus projetos de vida, o que trouxe a importância da memória.

Atendendo aos pressupostos de Delory-Momberger (2008), todos os participantes foram organizados em tríades e colocados em situação de rememoração, acontecendo o primeiro encontro entre os 12 integrantes para a apresentação das regras da participação, assim como para que assumissem ou não o compromisso de permanência. Em nosso estudo, a opção foi pela organização de três encontros para cada tríade sendo o primeiro dirigido a reflexões sobre o passado, o segundo sobre o presente e o terceiro ao futuro, o que resultou na produção de 36 (trinta e seis) narrativas.

Os encontros propiciaram o compartilhamento de experiências, apresentação de elementos e fatos importantes relacionados à trajetória da formação e com isto, a aquisição de dados para a análise do significado do processo de escolarização, em diferentes tempos da vida de cada um e em relação à repercussão do processo formativo sobre a vida profissional. Também foi oportunizada reflexão sobre a concretização ou não dos projetos de vida na perspectiva de que "[...] a relação com o passado está implicada numa antecipação e numa projeção do futuro, e a reconstrução desse passado está prenhe de uma intencionalidade mais ou menos definida" (DELORY-MOMBERGER, 2008, p. 100).

A realização das rememorações no coletivo nos remeteu a Halbwachs (2004, p. 58) que aponta na interpretação de situações de compartilhamento e rememoração de eventos, a presença de novos elementos trazidos pelo outro, o que enriquece as lembranças dos participantes e, consequentemente, os relatos do grupo. Sendo a memória coletiva resultado das representações humanas no presente, temos, segundo o autor, o 
resgate das experiências como um exercício propício a novas interpretações pelos integrantes do grupo.

Assim, para este estudo, a exposição da memória situada num dado contexto, propiciou elementos de identificação aos participantes na reconstrução do contexto vivido, assim como o agregar de elementos muitas vezes esquecidos e que possibilitaram o redesenho do quadro das suas trajetórias, na consideração dos acontecimentos como aqueles que também podem ser os:

[...] 'vividos por tabela', ou seja, acontecimentos vividos pelo grupo ou pela coletividade à qual a pessoa se sente pertencer. São acontecimentos dos quais a pessoa nem sempre participou, mas que, no imaginário, tomaram tamanho relevo que, no fim das contas, é quase impossível que ela consiga saber se participou ou não (POLLAK, 1992, p. 2).

Esta característica, que tem se ampliado perante a difusão da comunicação virtual, compõe os riscos a que se submetem os pesquisadores que se dedicam ao estudo de narrativas que resultam das interações sociais.

Amaral e Cabral (2010, p. 53) relatam que o processo de rememoração dado no coletivo, em pequenos ou médios grupos, propicia a reflexão sobre percursos de vida, reconstruídos com a perspectiva da identidade atual, ressignificando-a na história coletiva, resgatando a memória social além da sua própria.

Ao se cruzarem os tempos individuais, uma solidariedade e segurança são gerados em ambiente no qual a experiência é expressa por meio de narrativas, o que propicia sua ressignificação na articulação das memórias individuais e coletivas, pois “Essa história que é nossa e dos grupos aos quais pertencemos, diz-nos quem somos, auxilia e fortalece nossa identidade, ilumina nosso caminho na busca de sentidos para o nosso ser/estar no mundo" (BRANDÃO, 2002, p. 15)

As histórias de vida são consideradas neste processo também como elemento constituinte do trabalho da pesquisa-formação ${ }^{4}$, o que para Josso (1999) vem se consolidando em diversos aspectos da pesquisa em educação relacionadas às trajetórias de formação de variados grupos sociais. Segundo a autora, as histórias de vida "[...] dão uma sensibilidade para a história do aprendiz e de sua relação com o conhecimento". (JOSSO, 1999, p. 13)

\footnotetext{
40 termo é utilizado por Marie-Christine Josso (1999) na intenção de unir pesquisa e formação dentro de um único processo com desdobramentos intelectivos simultâneos.
} 
0 que temos conforme a autora é que:

[...] as relações entre histórias de vida e projeto podem ser apresentadas em torno de dois eixos que se nutrem mutuamente: a busca do projeto teórico de uma compreensão biográfica da formação e, a fortiori, da autoformação mediante os procedimentos de pesquisa-formação, de um lado, e, de outro, o uso de abordagens biográficas postas a serviço de projetos \{projetos de expressão, projeto profissional, projeto de reinserção, projeto de formação, projeto de transformação de práticas, projeto de vida\}. (JOSSO, 1999, p. 14)

A situação de diálogo para a rememoração sobre as experiências na formação e repercussão nos projetos de vida dos participantes foi norteada pelas temáticas e ampliada por questões apresentadas a cada encontro, sem que na mediação houvesse interferência que restringisse suas expressões. Ao gravarmos as narrativas obtivemos o registro de intermitências motivadas pela emoção, fornecendo o sentido e importância de 'dar voz' ao outro, principalmente pelo fato de que se a pessoa:

[...] não estiver numa situação social de justificação ou de construção de você próprio, como é o caso de um artista ou de um político, é estranho. Uma pessoa a quem nunca ninguém perguntou quem ela é, de repente ser solicitada a relatar como foi a sua vida, tem muita dificuldade para entender esse súbito interesse. Já é difícil fazê-la falar, quanto mais falar de si (POLLAK, 1992, p. 13).

Nossa preocupação na presente pesquisa foi conduzir os procedimentos de forma que o valor documental dos depoimentos não fosse comprometido no entendimento que Pollak (1992) defende ao considerar que:

[...] é óbvio que a coleta de representações por meio da história oral, que é também história de vida, tornou-se claramente um instrumento privilegiado para abrir novos campos de pesquisa. Por exemplo, hoje podemos abordar o problema da memória de modo muito diferente de como se fazia dez anos atrás. Temos novos instrumentos metodológicos, mas, sobretudo, temos novos campos. [...]. 0 que se tem feito recentemente, como por exemplo, a história da auto-apresentação das elites de um país, e também a história da cultura popular, ou da autopercepção popular, é, a meu ver, uma história perfeitamente legítima (POLLAK, 1992, p. 8).

\section{Os egressos da EJA como sujeitos sociais do diálogo}

Segundo Oliveira (1999, p. 59), o adulto participante dessa modalidade é geralmente o migrante e a migrante que chegam às grandes metrópoles oriundas de áreas rurais já bastante desgastadas e empobrecidas. São trabalhadores de ocupações urbanas com experiência no trabalho rural na infância e adolescência, que buscam a escola tardiamente para alfabetizar-se ou cursar algumas séries do ensino supletivo. Recém-incorporado ao 
território da antiga educação de adultos estão os jovens, conforme estudos de Romão e Gadotti (2007). Ele, o jovem, como um excluído da escola, teve sua presença incorporada aos cursos supletivos em fases mais adiantadas de escolaridade. Ligado ao mundo urbano exerce atividades de trabalho e lazer mais próximas da sociedade letrada, escolarizada e urbana.

Os perfis acima descritos correspondem aos educandos egressos do SESC e participantes deste estudo, onde na maioria das narrativas aparece a origem como advinda da zona rural, normalmente de municípios da região norte do Paraná e das imediações da área urbana de Londrina.

Efetivado o grupo, estabelecemos o diálogo com os 12 egressos divididos em tríades e a cada encontro e temática, os participantes assumiam, alternadamente, o seu papel de autor/narrador, o de escriba e o de consciência. Seguindo a proposição metodológica de Delory-Momberger (2008), a alternância de papéis acontece de acordo com a ordem das narrativas, assim, o primeiro narrador ao apresentar suas memórias, tinha o registro por escrito de sua fala pelo segundo componente, ficando o terceiro incumbido de, caso ocorresse alguma contradição ou obscuridade na narrativa, realizar a intervenção solicitando esclarecimentos. Assim, seguiam as narrativas, alternando-se os papéis na tríade. Para preservar os participantes, suas identidades foram substituídas pela inicial “E” de Egresso e a ordem numérica no interior de cada tríade (E1, E2, E3) acrescida de acordo com a adesão de cada participante pelo número da tríade como (T1, T2, etc.), denominando-se assim cada participante por E1T1 e assim sucessivamente.

No primeiro encontro do grande grupo foi firmado um compromisso, de que aconteceriam, no mínimo, três encontros com periodicidade semanal. Cada encontro foi permeado por uma temática específica pré-estipulada para a pesquisa, de acordo com os objetivos nela propostos: 1) trajetória do processo de escolarização; 2) experiência escolar vivida na instituição e 3) repercussões do processo de formação na vida prática. $05^{\circ}$ e último encontro foi realizado com a presença de todos para a socialização das narrativas. A devolutiva dos impactos no processo formativo foi realizada via correio eletrônico por cada um dos participantes às pesquisadoras.

Entre os sujeitos que aceitaram compartilhar suas histórias de vida emergiu a categoria gênero, o que se evidenciou na própria composição do 'grande grupo' com a presença de oito mulheres e quatro homens. Segundo Pinho (2003), o conceito de gênero 
é entendido como o “[...] conjunto de normas, valores, costumes e práticas através das quais a diferença biológica entre homens e mulheres é culturalmente significada [...] indicando construções sociais" (PINHO, 2003, p. 54). Para Fischer e Marques (2012, p. 4), o fenômeno da exclusão social da mulher é secular e este se dá no campo econômico, político e social se desdobrando para a cultura, a educação, o trabalho, a etnia, entre outros.

De acordo com Rieger (2010, p. 7), durante muito tempo a ideologia apregoou que a educação era prioridade dos homens, ficando a mulher com a incumbência de assumir os cuidados com a família e a casa. Esta lógica se evidencia em narrativas como a de E1T4 que é afrodescendente quando menciona que "[...] meu pai só deixou meus irmãos irem pra escola, eu não podia, por que ele achava que mulher se aprendesse a escrever era pra mandar carta pra namorado, aí ele não deixou eu estudar e o meu sonho foi ficando... ficando [...]' (E1, 33 anos, tríade 4).

As restrições ao acesso pleno à escola até meados da segunda metade do século XX carecia de ações que visassem sua democratização, sendo permeada esta restrição por inúmeras questões, dentre elas, a questão socioeconômica, de gênero e da discriminação racial. Destaque-se que a questão racial foi ignorada na legislação, até 05 de janeiro de 1989, quando foi instituída a Lei 7.716 que definiu os crimes resultantes de preconceito de raça ou de cor, bem como as respectivas penalidades (BRASIL, 1989). Desta forma, na análise da primeira temática, a repercussão da questão de gênero na escolarização da mulher aliada à questão racial foi ressaltada.

A presença e permanência de alunos afrodescendentes na escola aconteceu em meio à resistência para esta inserção, perante a discriminação em questões pedagógicas e o tratamento dispensado no ambiente escolar. Tal contexto é expresso no relato de E1T1 ao esclarecer que:

Comecei a estudar com seis anos de idade, tive alguns problemas, $o$ principal dele foi o preconceito devido a cor negra, terminei a minha primeira série com oito anos de idade, aí, logo que eu entrei na escola foi... todos... momentos bem complicados... de preconceito porque naquela época uma pessoa negra na escola era muito judiada [...] (E1, 32 anos, tríade 1). 
Menezes (2002) faz uma analogia entre o "mito de Narciso" citado na música de Caetano Veloso ${ }^{5}$ ao fato de que geralmente nos apaixonamos pelo o que é nosso e que ao olhar para o outro, buscamos o que nos é familiar e quando não encontramos a nossa imagem refletida, percebemos a diferença como a manifestação do 'mau gosto', sendo frequentemente repudiada, discriminada e até odiada. É contexto no qual, para Berger (1991, p. 6) “[...] a dignidade humana é uma questão de permissão social”, sendo esta afirmação coerente com o preconceito, ao não reconhecer este a dignidade do sujeito, comprometendo a sua inclusão social.

O contexto socioeconômico constituiu outro elemento limitador do processo de escolarização nas narrativas dos egressos que o indicaram de forma recorrente, como E2T4 que relata:

Minha infância foi dura para uma criança que sempre quis brincar e não podia, pois tinha que cuidar de meus irmãos mais novos, pois éramos pobres [...] eu não tinha tempo para brincar, pois aos dez anos de idade comecei a trabalhar para ajudar na renda da família, não tive oportunidade para continuar meus estudos (E2, 44 anos, tríade 4).

Também E1T1 enfatizou sua necessidade de suprir a demanda do sustento da família em detrimento de sua escolarização: “Tinha que dar um jeito de trabalhar [...]. Aí conversei com um vizinho que tinha uma... um bazarzinho [...] ele sabia bem da nossa vida, das nossas dificuldades [...]. Aí, fui trabalhar de, de pacoteira [...]' (E1, 32 anos, tríade 1).

Esses egressos demonstram o que Barros, Henriques e Mendonça (2000) consideram como categoria que não pode ser definida de forma única e universal, pois a pobreza se refere a 'situações' de carência em que os indivíduos não conseguem manter um padrão mínimo de vida condizente com as referências socialmente estabelecidas em cada contexto histórico. 0 que se constata é que ao falarmos de pobreza, miséria e indigência, também nos referimos à ausência de políticas para o atendimento às necessidades básicas da população, que neste distanciamento dos direitos sociais chega a colocar a educação como produto de 'luxo' e não como ‘direito social'.

Assim, a condição socioeconômica ainda se constitui como elemento importante no processo de aquisição e acesso a serviços educacionais mesmo sendo tais direitos

\footnotetext{
5 "SAMPA" letra e música de autoria de Caetano Veloso, interpretada por ele mesmo. Lançada em 1978 no Álbum "Muito - dentro da estrela azulada" pela gravadora CBD Phonogram.
} 
legalmente assegurados à população, mas que, não se encontram disponíveis para grande parcela desta mesma população. Neste sentido, a EJA se desenvolve com muitas funções, e entre elas a de resgatar o direito à educação escolar que foi negado a tantas pessoas. Cabe à EJA provocar uma reinserção dos sujeitos visando também um resgate da consciência destes direitos por parte dos que nela ingressam.

\section{SESC - CEBJA: metodologia, ensino e aprendizagem}

Analisando a Proposta Pedagógica do SESC Londrina, campo deste estudo, constatamos abordagem que contempla os pressupostos do pensamento freireano na preocupação com a inserção dos estudantes da EJA no mercado de trabalho, e concomitante a isso propiciar-lhes as condições para a construção de uma consciência social libertadora, no sentido de que possam identificar seus direitos, inclusive ao trabalho e por eles lutarem (SESC, 1999, p. 21).

Sendo o público escolar da EJA conforme Santos (2001), aqueles que viveram 'percalços e interrupções nos estudos' antes de lá chegarem, tem-se a modalidade de ensino que se constitui com pessoas que carregam em suas histórias a dupla exclusão: a vivida precocemente e a da escolarização tardia em meio a constrangimentos sociais diversos. Tal perspectiva amplia a importância da compreensão do processo de exclusão e da reinserção enquanto fenômeno do sistema educacional brasileiro, ao serem tais fenômenos experiências que sujeitos específicos vivenciaram e sofrem suas repercussões na vida.

Na perspectiva de Arroyo (2006), a juventude e a vida adulta trazem consigo um tempo de marcas de socialização e de sociabilidade, de formação e intervenção, sendo esses "tempos de vida" do jovem e do adulto, tempos que devem ser tratados como "tempos de direito", que culminam na urgência da elaboração de políticas públicas dirigidas à garantia da pluralidade de seus direitos e ao reconhecimento de seu protagonismo na sociedade.

O SESC - Londrina, instituição campo desta pesquisa, utiliza os projetos interdisciplinares como estratégia de ensino-aprendizagem, visando à transformação social na democracia e consequentemente o exercício da cidadania (SESC, 1999).

Um projeto interdisciplinar requer o diálogo entre os sujeitos aprendizes e as diversas disciplinas existentes no currículo escolar, um processo de aprendizagem, que se 
constitui também como espaço de conflito e que propiciará esforços para se atingir um determinado saber. Quando um grupo de alunos pesquisa acerca do 'Movimento Sem Terra', não apenas a Geografia estará presente no trabalho acerca da caracterização das áreas geográficas ocupadas, também a História com o processo de construção do conceito de propriedade privada, das disputas por territórios, valores relacionados à terra, entre outros. Também a Sociologia com o trato da questão acerca do direito a se ter direitos, a Língua Portuguesa com a compreensão das variações linguísticas, entre outros elementos que irão surgindo no decorrer dos estudos. Com isto, se pretende atingir o que para Santomé (1997, p. 5) deve concretizar a oferta aos educandos de parcelas da realidade para a sua análise e conhecimento.

De acordo com a proposta pedagógica do SESC Londrina, a metodologia com base nos projetos interdisciplinares auxilia na aquisição das aprendizagens significativas, por meio de temas geradores relacionados ao universo de vida e contexto dos alunos, articulados aos diversos conteúdos estabelecidos na Base Nacional Comum, definida para todas as instituições que trabalham com a modalidade. 0 tema gerador possibilita ao estudante que construa significados referentes ao que está estudando, o que pode ser facilitado na consideração dos saberes prévios, gerando o novo conhecimento e redimensionamento do senso comum da vida prática.

O percurso de construção do conhecimento, em que cada evento tem ligação com uma estrutura pré-existente, ou seja, em que o estudante utiliza os conhecimentos prévios para entender os novos saberes, favorece a aprendizagem e the dá sentido. É a 'aprendizagem significativa' o que se objetiva e que para Ausubel, Novak e Hanesian (1980) acontece em processo de ensino que favoreça ao educando a construção de significados sobre determinado objeto de aprendizagem. Isto quer dizer que o conteúdo novo deverá estar ligado a estruturas conceituais já existentes no processo cognitivo do estudante.

Tal pressuposto se coaduna ao que preconiza Freire (2005), que ressalta a presença das vivências e experiências dos educandos como ponto inicial do processo educativo em uma relação dialógica e democrática. É a educação por meio da problematização pelos sujeitos na relação com o mundo o que possibilita a superação do que chama de "educação bancária" que define como uma “[...] única margem de ação que se oferece aos educandos é a de receberem os depósitos, guardá-los e arquivá-los” (FREIRE, 2005, p. 66). Nesta perspectiva, a concretização da 'aprendizagem significativa' trará para a organização dos 
conteúdos possibilidades para a investigação da realidade e da cultura do educando, tornando-se aprendizagem efetiva ao compor o projeto de vida das pessoas.

Nesta perspectiva, a formação dos professores no Brasil que tem sido alvo de inúmeras críticas e questionamentos, repercute sobre o professor que atua na EJA ao exigir que se aproximem, minimamente, das condições pedagógicas necessárias ao trato junto ao público de EJA. Tal demanda esbarra em um dos problemas que a EJA enfrenta hoje de acordo com Arroyo (2006), que é o fato de que muitos profissionais que atuam na formação de alunos de nível fundamental e médio sejam, na maioria das vezes, os mesmos que atuam com alunos da EJA o que gera práticas pedagógicas não adequadas ao público e às especificidades da EJA.

Freire (1996) considera que ensinar não é transferir conhecimentos e conteúdos e que formar não é a ação pela qual um sujeito criador dá forma ou alma a um corpo indeciso e acomodado. Afirma que ensinar exige, acima de tudo, respeito aos saberes dos educandos, que são formados e socialmente construídos na prática comunitária, não se limitando $o$ ato de educar aos 'conteúdos' ao ter como princípio a necessidade de uma troca efetiva de informações e de conhecimento entre educador e educando.

É nesta complexidade que Borgh (2007) inscreve o desafio de ser educador de uma modalidade de ensino que, historicamente, é representada no cenário educacional, como dirigida às classes populares dilaceradas pela desigualdade social e marcadas pela negação de direitos essenciais. A dimensão desta superação está em dar significado à ação pedagógica possibilitando o seu reconhecimento social.

A luta por uma metodologia de ensino que fuja do cunho bancário, tão criticado em especial por Paulo Freire, deve ser intensa e diária por parte dos educadores. Conforme explica Xavier (2010), são muitos os desafios que nos impelem a questionamentos em função da especificidade e diversidade das salas de EJA, dentre eles: quais as práticas educativas que possibilitam a aprendizagem significativa de diferentes estudantes? Quais os processos de comunicação que permeiam essas práticas? Quais as possibilidades de desenvolver uma ação educativa que considere a diferença? E por fim: como conectar contextos tão diferentes? Para a autora, os estudantes de EJA, ao retornarem à escola buscam aprender o que possui significado para eles, aquilo que conseguem articular mentalmente e interativamente com o que vivem, ou seja, com as dimensões do trabalho e da produção da própria vida (XAVIER, 2010, p. 140). 
Sendo estes os princípios básicos expostos no projeto implementado pelo SESC Londrina para a EJA, no próximo item trazemos algumas das dimensões do significado de retorno ao sistema educacional por meio da EJA para os estudantes, assim como sobre a trajetória no SESC e a repercussão dos objetivos da instituição no processo de formação dos mesmos na relação com a vida prática.

\section{Narrativas sobre o retorno aos estudos e repercussão nos Projetos de Vida}

Da compreensão da necessidade de retorno aos estudos até a decisão de realizar a matrícula para frequentar o curso há um longo caminho. 0 adulto trabalhador, imerso em responsabilidades de todos os tipos e níveis como o trabalho, a família, filhos, questões relacionadas à saúde, finanças, entre outros, encontra diversos elementos que o mantém longe do retorno à sua escolarização como explica E2T1: “[...] eu reprovei a $6^{a}$ série, fiz um ano no Colégio São Paulo, aí eu fiquei grávida e parei de estudar também. Fui mãe com 16 anos [...] eu não tinha com quem deixar meu filho [...] com isso eu fiquei mais de cinco anos sem estudar [...]' (E2, 31 anos, tríade 1).

Para as mulheres a imposição familiar, a gravidez precoce e a necessidade da subsistência e cuidado com os filhos são fatores determinantes em suas escolhas, tal como relata a egressa E1T3: “[...] Meu pai era muito severo e achava que mulher tinha que casar cedo pra não 'se perder' na vida. Aí arrumou um marido pra mim e eu tive que sair da escola, casei com quinze anos, fui mãe aos dezesseis” (E1, 61 anos, tríade 3).

E3T1, com 39 anos de idade, nos demonstra como as adversidades são inúmeras e perpassam as histórias de vida que vão se delineando em opções voluntárias ou não que repercutem profundamente ao dizer que "[...] me envolvi com álcool e meu irmão com drogas, devido a desestrutura familiar e em definitivo veio a separação de meus pais e consequentemente tive que trabalhar e aí a qualidade na escola caiu mesmo" (E3, 39 anos, tríade 1).

Ao efetuar a tentativa de retorno, eles chegam repletos de expectativas as quais vão sendo satisfeitas ou não no decorrer do curso. De acordo com Vieira (1999, p. 344), um projeto de vida só é possível quando há ações com objetivos pré-determinados implicando por parte do sujeito, uma antecipação de um futuro ideal. Isso significa que o sujeito 
delimite sua caminhada entre as vias alternativas a serem seguidas e que sua escolha entre uma ou outra seja consideravelmente refletida.

Entender que significativa é a aprendizagem que o aluno possa, em determinado contexto utilizar, pois consegue generalizá-la, ou seja, transpô-la para outras esferas que não a escolar, torna a formação e conclusão do curso em nível médio e profissionalizante, para estudantes da EJA em especial, um momento de extrema importância e significado.

Os relatos sobre este momento apontam para a importância da celebração do fim de uma etapa que para eles foi conquistada a 'duras penas', em função de suas dinâmicas de vida de trabalhadores e pessoas com afazeres diversos e inúmeras responsabilidades conforme se constata em E1T2:

\begin{abstract}
Sinceramente eu achei que eu fosse morrer sem terminar o ensino médio, não que não tivesse vontade, mas as condições eram nada boas [...] eu tinha receio de como seria tratado depois de tanto sofrimento, cheguei inseguro, não tenho vergonha de falar, mas essa insegurança foi sumindo aos poucos, tudo o que eu queria era ser um bom aluno, cumprir com minhas obrigações e acho que consegui [...](E1, 38 anos, tríade 2).
\end{abstract}

Os egressos, ao finalizarem o curso de EJA na instituição pesquisada, levaram com seus 'canudos' uma expectativa relacionada ao alcance de melhores empregos, ascensão de cargo no ambiente de trabalho, ingresso em outras posições, enfim, aspirando melhorias nas suas condições de vida, tal como E2T3 explica: "Posso afirmar de que realmente vale a pena fazer EJA. Para sua vida profissional e pessoal faz toda a diferença! Entrei na UEL e estou fazendo Pedagogia, era o meu sonho ser professora! Ainda tô no segundo ano, mas se Deus quiser eu chego lá [...]' (E2, 35 anos, tríade 3).

Os sujeitos sociais egressos da EJA indicam que, em relação ao mercado de trabalho buscaram colocar-se ou recolocar-se dentro de seus respectivos contextos e possibilidades. Alguns ainda nas mesmas condições profissionais de quando ingressaram no curso como E2T1 que explica: “Permaneço na mesma profissão, doméstica, mas muitas coisas eu vejo de forma diferente. Concluí que me falta um pouco de vergonha na cara para entrar numa faculdade [...]" (E2, 31 anos, tríade 1). Nesta narrativa destacamos que há outra perspectiva, que é o reconhecimento do potencial de mudança que tem para o seu futuro, o que poderá levá-la a uma maior mobilidade, rumo aos seus objetivos pessoais e profissionais.

E2T2 se encontra em outra condição ao ter obtido progressão referente ao cargo, sendo que para ela, nesta formação: “Aprendi muitas coisas no dia-a-dia. Como nossa 
vida pode mudar em segundos... hoje trabalho no laboratório da SANEPAR e passei no concurso. Estou esperando ser chamada” (E2, 42 anos, tríade 2).

Considerando todos os percalços vividos pelos egressos participantes desta pesquisa, foi possível perceber por meio das narrativas o "movimento" ocorrido em suas trajetórias, seus objetivos e aspirações. Cada um deles fez e refez os seus planos e assim por meio das reflexões ocorridas durante os encontros, novas metas e caminhos foram redesenhados para o retorno à busca de uma realização ainda maior que a obtida com a conclusão da educação básica.

\section{Considerações Finais}

Constatamos que o trabalho de formação realizado pela instituição SESC-Londrina expresso em seu Projeto Político Pedagógico para a EJA, bem como os impactos na vida prática e profissional dos alunos atendidos pela instituição entre 2004 a 2007, apesar de suas limitações e contradições, efetivou a sua proposta. Observamos também que ela gera expectativas e memória afetiva positiva, o que leva os egressos a defenderem a instituição e metodologia adotada, apesar das dificuldades para sua efetivação.

Nesta investigação, transformada em processo de aprendizagem, pois tal como Delory-Momberger (2008) preconizou, as histórias de vida são muito mais que narrativas ao vento, ela constituiu-se também como verdadeira experiência de formação e auto-formação. Tais elementos foram evidenciados por meio dos relatos realizados como proposta de finalização para a pesquisa, quando os educandos realizaram um balanço da incidência de suas participações no presente estudo conforme expressa E3T2:

Então Cláudia, o que pra mim disso tudo foram várias coisas, mas o que mais mexeu de verdade foi com o fato de que a gente percebeu que a vida não pode parar. Que a gente tem que tá sempre buscando e que se a gente para, as coisas continuam caminhando e a gente é que fica pra trás. Já foi assim quando eu deixei de estudar lá atrás e se eu me descuidar vai acontecer tudo de novo e eu vou ter que tá sempre correndo atrás do prejuízo [...] (E3, 54 anos, tríade 2).

Por intermédio desta pesquisa registramos o impacto positivo da possibilidade de viabilizar contexto para produção de narrativas no coletivo e em relação de alteridade, o que contribuiu para a rememoração que no processo possibilitou o 'reconhecimento de si e do outro’ em sua 'história de formação’ como sujeito social. 


\section{Referências}

AMARAL, R.; CABRAL, P. Oficina memória viva: intervenções em diferentes espaços (auto) biográficos. Revista Portal de Divulgação, São Paulo, n. 2, set. 2010.

ARROYO, M. Formação de educadores de jovens e adultos. Belo Horizonte: Secretaria da Educação, 2006.

AUSUBEL, D. P.; NOVAK, J. D.;HANESIAN, H. Psicologia educacional. Tradução de Eva Nick. Rio de Janeiro: Editora Interamericana Ltda,1980.

BARROS, R. P.; HENRIQUES, R.; MENDONCA, R. Desigualdade e pobreza no Brasil: retrato de uma estabilidade inaceitável. Revista Brasileira de Ciências Sociais, São Paulo, v. 15, n. 42, p. 123-142, 2000. Disponível em: https://doi.org/10.1590/S010269092000000100009. Acesso: 5 jun. 2020.

BERGER, P. Perspectivas sociológicas. a sociedade no homem. Petrópolis: Vozes, 1991.

BORGH, I. S. M. Formação de educadores da EJA: inquietações e perspectivas. Salvador: Universidade Federal da Bahia, 2007.

BRANDÃO, V. M. T. Oficina de memória: teoria e prática: relato sobre a construção de um projeto. Revista Kairós Gerontologia, São Paulo, v. 5, n. 2, p. 181-195, 2002.

BRASIL. Lei no 7.716, de 5 de Janeiro de 1989. Define os crimes resultantes de preconceito de raça ou de cor. Brasília: Presidência da República, 1989. Disponível em: http://www.planalto.gov.br/ccivil_03/leis/l7716compilado.htm. Acesso: 6 jun. 2020.

DELORY-MOMBERGER, C. Biografia e educação: figuras do indivíduo-projeto. Tradução Maria da Conceição Passegi, João Gomes da Silva Neto e Luis Passegi. Natal, RN: EDUFRN; São Paulo: Paulus, 2008.

FISCHER, I.; MARQUES, F. 113 - gênero e exclusão social. Textos Para Discussão, [Brasília], n. 113, p.1-13, 2012. Disponível em: https://periodicos.fundaj.gov.br/TPD/article/view/928. Acesso em: 28 jul. 2019.

FREIRE, P. Pedagogia da Autonomia: saberes necessários à prática educativa. São Paulo: Paz e Terra, 1996.

FREIRE, P. Educação e mudança. Tradução de Moacir Gadotti, Lillian Lopes Martin. Rio de Janeiro: Paz e Terra, 1997.

FREIRE, P. Pedagogia do oprimido. São Paulo: Paz e Terra, 2005.

HALBWACHS, M. A memória coletiva. São Paulo: Centauro, 2004.

JOSSO, M. C. História de vida e projeto: a história de vida como projeto e as "histórias de vida" a serviço de projetos. Tradução de Denice B. Catani, helena C. Chamlian. Educação e Pesquisa, São Paulo, v. 25, n. 2, p. 11-23, jul./dez. 1999. 
MENEZES, W. O preconceito racial e suas repercussões na instituição escola. Recife: Fundação Joaquim Nabuco, 2002. (Trabalhos para Discussão, n. 147/2002). Disponível em: http://www.fundaj.gov.br/tpd/147.html. Acesso em: 24 Jan. 2020.

OLIVEIRA, M. K. Jovens e adultos como sujeitos de conhecimento e aprendizagem. Revista Brasileira de Educação, Rio de Janeiro, n. 12, p. 59-73, 1999.

PINHO, M. J. S. Abordagens de gênero e educação: estratégia para a igualdade e liberdade. In: ENCONTRO DE PESQUISA EDUCACIONAL DO NORTE E NORDESTE, 2003, Maceió. Anais [...]. Maceió: UFAL, 2003.

POLLAK, M. Memória e identidade social. Estudos Históricos, Rio de Janeiro, v. 5, n. 10, p. 200-212, 1992.

RIEGER, M. Mulheres na educação de jovens e adultos. mobilizações para a reconstrução do percurso de escolarização. Sinop: Universidade do Estado de Mato grosso, 2010. Projeto de Pesquisa.

ROMÃO, J. E.; GADOTTI, M. Educação de adultos. identidades, cenários e perspectivas. Brasília: Líber Livro editora, 2007.

SANTOMÉ, J. T. Política educativa, multiculturalismo e práticas culturais democráticas nas salas de aula. Revista Brasileira de Educação, Rio de Janeiro, n. 4, p. 5-25, 1997.

SANTOS, G. L. Educação ainda que tardia a exclusão da escola e a reinserção em um programa de educação de jovens e adultos entre adultos das camadas populares. 2001. Dissertação (Mestrado em Educação) - Faculdade de Educação, Universidade Federal de Minas Gerais, Belo Horizonte, 2001.

SESC - SERVIÇO SOCIAL DO COMÉRCIO. Projeto político-pedagógico para educação de jovens e adultos. ensinos fundamental e médio: SESC Londrina/Paraná. Curitiba: SESC, 1999. Divisão de Apoio Operacional.

VIEIRA, R. Histórias de vida e identidades, professores e interculturalidades. Porto: Edições Afrontamento, 1999.

XAVIER, M. R. S. Comunicação, conhecimento e docência: dimensões do processo de formação de educadores no contexto da educação de jovens e adultos. 2010. Tese (Doutorado) - Universidade Federal de Santa Catarina, Florianópolis, 2010. 